\section{YEARS \\ Cerebrovascular \\ Diseases}

\title{
Stroke in Myopathies
}

\author{
Josef Finsterer $^{a} \quad$ Claudia Stöllberger $^{b}$ \\ ${ }^{a}$ Neurological Department and ${ }^{\mathrm{b} S e c o n d ~ M e d i c a l ~ D e p a r t m e n t, ~ K r a n k e n a n s t a l t ~ R u d o l f s t i f t u n g, ~ V i e n n a, ~ A u s t r i a ~}$
}

\section{Key Words}

Genetics - Myocardium - Dilated cardiomyopathy · Atrial fibrillation - Neuromuscular disorder - Cerebral infarction • Stroke-like episode

\begin{abstract}
Objectives: Only few data are available about the risk of myopathy patients experiencing a cerebral stroke. Aims: To review the current knowledge about the frequency, pathogenesis, and outcome of stroke in primary/secondary myopathies. Methods: Literature review of all human studies dealing with stroke in primary/secondary myopathies. Results: Stroke in myopathies may be either ischemic, metabolic, or cryptogenic. Ischemic stroke may be further classified as cardioembolic, angiopathic, hemodynamic, or thrombophilic. Cardioembolic stroke occurs if there is cardiac involvement in the form of atrial fibrillation/flutter, dilated cardiomyopathy, or non-compaction. Angiopathic stroke occurs if there is atherosclerosis (frequently associated with mitochondrial disorders (MIDs), vasculitis, or dissection in inflammatory myopathies) or MIDs. Thrombophilic stroke may occur in poly-/dermatomyositis if there is additional antiphospholipid syndrome. Metabolic stroke usually manifests as stroke-like episode and is a distinct feature of various MIDs, particularly MELAS syndrome. The clinical manifestations are due to a vasogenic edema, showing up as hyperintensity on $\mathrm{T}_{2}, \mathrm{DWl}$, and apparent diffusion coefficient mapping. Differentiation between ischemic and metabolic stroke is essential in terms of diagnosis, therapy, and prog-
\end{abstract}

nosis. Conclusions: Ischemic stroke due to cardioembolism, arteriopathy, or thrombophilia are rare events in myopathies, but metabolic stroke is a frequent feature of MIDs, with distinct diagnostic and therapeutic implications.

Copyright $\odot 2009$ S. Karger AG, Basel

\section{Introduction}

At a first glance, the association between primary and secondary myopathies (MPs) and stroke does not seem to be plausible (see 'Appendix' for a list of MPs). When looking more deeply into the field, however, it turns out that there are a number of clinically relevant associations and even causal relations between MPs and stroke. According to the pathogenesis, stroke in MPs may be principally classified into 6 categories: cardioembolic, angiopathic, hemodynamic, thrombophilic, metabolic, and cryptogenic stroke. This mini-review gives an overview of the current knowledge and future perspectives concerning the types of MPs associated with stroke, the pathogenetic background of stroke in MPs, and the treatment and outcome of stroke in MPs.

\section{Frequency of Stroke in Myopathies}

Most data about stroke in MPs derive from single cases or case series, and only rarely from retrospective cohort studies. In one of the first studies on the frequency

\section{KARGER \\ Fax +4161306 1234 \\ E-Mail karger@karger.ch}

www.karger.com
(C) 2009 S. Karger AG, Basel

1015-9770/10/0291-0006\$26.00/0

Accessible online at:

www.karger.com/ced
Josef Finsterer, MD, PhD

Postfach 20

AT-1180 Vienna (Austria)

Tel. +43171165 92085, Fax +4314781711

E-Mail fifigs1@yahoo.de 
of stroke in MPs - from among 52 patients with $\mathrm{Du}$ chenne muscular dystrophy (DMD), 61 patients with myotonic dystrophy (dystrophia myotonica) type 1 (DM1), 14 patients with Becker's muscular dystrophy (BMD), and 4 patients with Friedreich's ataxia, collected during a period of 18 years and followed up every 6 months for 3-17 years - the prevalence of stroke was only $1.5 \%$, and thus not increased compared to the nonmyopathic population [1]. Among the 2 patients who experienced a stroke, 1 had DM1 and the other Friedreich's ataxia. Both patients had atrial fibrillation (AFI)/atrial flutter (AFL) and both patients presented with reduced systolic function [1], the reason why stroke was attributed to cardioembolism in both patients. The low rate of stroke in this study may be due to the restriction of the study to only 3 types of primary MPs. Since a total of 4 patients of the cohort had AFI/AFL, 50\% of these patients developed a stroke [1]. The frequency of stroke in DMD has been systematically investigated by Hanajima and Kawai [2] in Japan. Among 665 DMD patients, stroke occurred in 5 of them (0.75\%) [2]. All 5 patients had dilated cardiomyopathy (dCMP) and 1 of them had AFI.

\section{Causes of Stroke in Myopathies}

\section{Cardioembolic Stroke}

After metabolic stroke, cardioembolic stroke is the second most frequent cause of stroke in patients with MPs. Cardioembolic stroke results from manifestations of primary or secondary MPs in the heart [3]. Cardiac involvement in MPs may affect the cardiac conduction system or, more frequently, the myocardium. Involvement of the myocardium in MPs may manifest as hypertrophic CMP, the apical form of hypertrophic CMP, left ventricular hypertrabeculation (LVHT)/non-compaction, dCMP, or restrictive CMP.

\section{Atrial Fibrillation/Flutter}

Involvement of the cardiac conduction system may manifest as impulse generation or impulse conduction abnormalities, which may remain subclinical and may be recorded exclusively on standard ECG, during a stress test, 24-hour ECG, or loop recording. The most relevant of these ECG abnormalities with regard to ischemic stroke is AFI/AFL [4]. AFI/AFL has been described in a number of MPs (table 1) [4], most frequently in patients with DM1, Emery-Dreifuss muscular dystrophy (EDMD), or dystrophinopathies (DMD, BMD) [4]. Primary and
Table 1. Myopathies in which AFI/AFL has been described

\author{
Primary myopathies \\ Duchenne muscular dystrophy \\ Becker's muscular dystrophy \\ Facioscapulohumeral dystrophy \\ $\mathrm{X}$-linked Emery-Dreifuss muscular dystrophy \\ Autosomal dominant Emery-Dreifuss muscular dystrophy \\ Laminopathy \\ Limb-girdle muscular dystrophies \\ Myofibrillar myopathy \\ DM1 \\ DM2 (PROMM) \\ Congenital fiber-type disproportion myopathy \\ Rigid spine syndrome \\ Desmin myopathy \\ Glycogenoses \\ Mitochondrial disorders \\ McLeod syndrome \\ Barth syndrome \\ Secondary myopathies \\ Dermatomyositis \\ Polymyositis/dermatomyositis \\ Polymyositis \\ Colchicine-induced rhabdomyolysis \\ Hyperthyroid myopathy
}

secondary stroke prevention in patients with MP and AFI is the same as in patients with other causes of AFI.

In a study on 18 patients with EDMD, AFI was recorded in 11 of them [5]. Four of these 11 patients (36\%) developed cardioembolic stroke. One of these 4 patients had X-chromosome-linked EDMD, and 3 had autosomaldominant EDMD [5]. All 4 patients had AFI/AFL at the time of the event [5]. Heart failure required heart transplantation in 1 of the 18 patients, and asymptomatic reduced systolic function occurred in another 3 patients [5]. The authors concluded that stroke can be the first manifestation of EDMD in young adults, and that it is frequently disabling [5]. In a patient with BMD and $\mathrm{dCMP}$, ischemic stroke developed during a period of AFI [6]. Stroke in DM1, preceded by a transitory ischemic attack (TIA), was first described in a 55-year-old male and attributed to mitral valve prolapse syndrome [7]. However, AFI was also recorded in this patient, which is why a cardioembolic stroke is more likely [7]. Among 5 DMD patients experiencing stroke, 1 had AFI and dCMP [2].

\section{Dilated CMP}

Among all CMPs, dCMP and LVHT are the most relevant for stroke. Since hypertrophic CMP can turn into dCMP, it has to be regarded as a potential source of cardio- 
embolism in patients with MPs as well. CMPs may be relevant for the development of stroke because they are frequently associated with reduced systolic function and AFI/ AFL. Reduced systolic function may cause cardioembolic stroke in cases of intracardiac thrombus formation or because of hemodynamic reasons. MPs in which dCMP has been described so far are listed in table 2. dCMP most frequently occurs in dystrophinopathies, mitochondrial disorders (MIDs), and limb-girdle muscular dystrophies [3].

Stroke in association with dCMP has been also described in a patient with Barth syndrome, who was in sinus rhythm at the time of the event [8]. Stroke in association with dCMP was also described in 2 patients with DMD (DMD sufferers develop dCMP by about 20 years of age in almost $100 \%$ of cases [9]). In 1 of these patients, stroke occurred at 21 years of age at an ejection fraction $(\mathrm{EF})<20 \%$, during sinus rhythm, and together with increased thrombin-ATIII complexes and increased D-dimer [10]. The second DMD patient experienced a TIA at 21 years of age, and 5 months later completed ischemic stroke. His EF was also $<20 \%$, he was in sinus rhythm, and also had increased thrombin-ATIII complexes and D-dimer [10]. Ischemic stroke in the absence of AFI/AFL was also reported in a 13-year-old DMD patient, in whom the EF was $35-40 \%$ at the time of the event [11]. Five months later, the patient experienced a minor stroke in the same vascular territory as before [11]. dCMP was the cardiac abnormality made responsible for stroke in $5 \mathrm{DMD}$ patients, aged 16-20 years, of whom 1 additionally had AFI [2]. Generally, dCMP seems to create a predisposition towards ischemic stroke, irrespective of its cause. In a study of 72 patients with dCMP, the prevalence of silent cerebral infarction was 39 and $27 \%$ in patients with ischemic and non-ischemic dCMP, respectively, and significantly increased compared to controls (3.6\%) [12]. Systolic function was lower in patients with silent cerebral infarction than without, and a restrictive diastolic filling pattern predisposed patients to silent cerebral infarction [12].

Left Ventricular Hypertrabeculation/

Non-Compaction

LVHT, also known as non-compaction, describes a cardiac abnormality of the left ventricular apex, the lateral wall, and (rarely) the septum that is characterized by a meshwork of interwoven myocardial strings lined with endocardium, which constitutes a spongy myocardial layer at the endocardial side, clearly distinct from the underlying compacted myocardium at the epicardial side (2-layered myocardium) [3, 13-15]. In up to $82 \%$ of the LVHT patients, an MP can be detected. MPs so far asso-
Table 2. Myopathies in which dilated cardiomyopathy has been reported

Dystrophinopathies

Laminopathies

Limb-girdle muscular dystrophies

Fukuyama-type congenital muscular dystrophy

Nemaline myopathy

Centronuclear myopathy

Congenital fiber-type disproportion

Desminopathy

Glycogenosis type IV

Mitochondrial disorders

Barth syndrome

Myofibrillar myopathy

Primary carnitin deficiency

ciated with LVHT are MIDs, dystrophinopathies, DM1, DM2, EDMD, zaspopathy, dystrobrevinopathy, Barth syndrome, or myoadenylate-deaminase deficiency [16]. LVHT is frequently associated with ECG abnormalities (75\% of newborns with LVHT) $[3,15,17,18]$, systolic dysfunction ( $83 \%$ of the children with congenital LVHT), or occasionally also with stroke/embolism $[3,15,18]$. Stroke in LVHT may not only derive from AFI/AFL or systolic dysfunction, but also from thrombus formation within the recessus of the myocardial meshwork.

Whether or not the risk of stroke is increased in patients with LVHT is controversial. Some studies found no increased frequency of stroke in LVHT patients [19-21], whereas others, particularly case reports, indicated an increased risk of developing a stroke (table 3) [22-25]. In a retrospective study of 229 patients with LVHT, of which those with AFI/AFL were excluded, only 4 patients had developed ischemic stroke during a mean follow-up of 7.3 years [19]. In a retrospective study on 62 LVHT patients, the incidence of stroke was $10 \%$ in patients and $15 \%$ in controls matched for age, sex and systolic function [21]. Whether or not patients with LVHT should generally receive oral anticoagulation (OAC) is controversial. Though OAC have been frequently proposed for patients with LVHT [26], these recommendations rely only on single case reports or small case series. According to our own experience, there is no general indication for OAC in LVHT patients as long as classical indications for OAC therapy are absent $[14,20]$.

\section{Angiopathic Stroke}

Angiopathies associated with stroke in MP patients include atherosclerosis, which frequently occurs in MIDs 
Table 3. Studies reporting stroke in LVHT patients

\begin{tabular}{lccl}
\hline & $\begin{array}{l}\text { Number of LVHT } \\
\text { patients investigated }\end{array}$ & $\begin{array}{l}\text { Number of patients } \\
\text { with stroke }\end{array}$ & Additional findings \\
\hline Fazio et al., 2008 [19] & 229 & 4 & decreased systolic function (50\% of pat.) \\
Finsterer et al., 2008 [20] & 104 & $16(15 \%)$ & $\begin{array}{l}\text { at least 1 classical risk factor in 15 patients } \\
\text { Sahin and Karsidag, 2009 [24] }\end{array}$ \\
Fazio et al., 2009 [22] & 1 & 1 & not reported \\
Sir et al., 2008 [25] & 1 & 1 & none \\
Oduncu et al., 2008 [23] & 1 & 1 & biventricular non-compaction \\
Nakajima et al., 2007 [60] & 1 & 1 & essential thrombocytosis \\
Celebi et al., 2008 [61] & 1 & 1 & systolic dysfunction \\
Baez-Escudero et al., 2008 [62] & 1 & 1 & stroke-like episodes, endocarditis \\
Finsterer et al., 2008 [63] & 1 & 1 & not reported \\
Fernández Sánchez et al., 2006 [64] & 1 & 6 & incidence of stroke lower than in controls \\
Walpot et al., 2005 [65] & 1 & 1 & 18-month-old girl, increased factor-VIII \\
Stöllberger and Finsterer, 2005 [21] & 62 & & \\
Hasçelik et al., 2003 [66] & 1 & & 1 \\
\hline
\end{tabular}

and DM1 in the presence of classical cardiovascular risk factors, dissection, or vasculitis in inflammatory MPs, such as polymyositis or dermatomyositis.

\section{Polymyositis}

A 53-year-old patient with polymyositis experienced cerebral hemorrhage and dissection of the right external iliac and right renal arteries. These findings were attributed to necrotizing angiitis [27]. Coarctation of the aorta, aortic stenosis, bicuspid aortic valve, and Marfan syndrome were excluded as possible causes of the arteriopathy. There was only mild arteriosclerosis and no cystic necrosis of the aortic media or other arteries. The only risk factor other than polymyositis for the development of necrotic angiitis was long-term therapy with steroids [27]. In a patient with polymyositis, 18 years after the onset of rheumatoid arthritis, the history was positive for stroke and myocardial infarction after high-dose steroids. Whether stroke was due to vasculitis or due to steroid-induced diabetic angiopathy in these patients remains elusive [28].

\section{Dermatomyositis}

In cases of intractable dermatomyositis, cerebral vasculitis may develop. A 47-year-old female with dermatomyositis developed ischemic stroke, attributed to cerebral vasculitis and confirmed by conventional angiography and biopsy of the cerebrum [29]. Dermatomyositis and vasculitis responded favorably to cyclophosphamide [29]. Acute ischemic stroke was also reported in another 47-year-old female with dermatomyositis, who received intravenous immunoglobulins when the stroke developed, which was why it remained unclear if the stroke was due to this treatment or concomitant vasculitis [30].

Mitochondrial Angiopathy

Whether there is a distinct mitochondrial macro- or micro-angiopathy is under debate at the moment. However, classical cardiovascular risk factors - such as diabetes, arterial hypertension, and hyperlipidemia - are frequently present in a number of syndromic and non-syndromic MIDs [31]. There are also patients with MID who developed severe atherosclerosis in the absence of classical cardiovascular risk factors [32]. In these cases, atherosclerosis could be a manifestation of the underlying MID, an assumption for which some evidence has been provided [33]. There are also some indications for mitochondrial microangiopathy, but the majority of the studies argue against such an entity in the pathogenesis of strokelike episodes (SLEs). In a patient with MELAS syndrome due to a mtDNA tRNA(Phe) mutation and an absence of classical atherothrombotic risk factors, recurrent embolic ischemic strokes developed because of carotid artery stenosis and artery-to-artery embolism into the middle and anterior cerebral artery [34].

\section{Thrombophilic Stroke}

When studying the coexistence of polymyositis/dermatomyositis and antiphospholipid syndrome in a cohort of patients, 3 patients presented with both conditions. One of these 3 patients not only developed livedo reticularis, recurrent abortions, and mitral regurgitation, but also isch- 
emic stroke. The patient additionally had lupus erythematosus [35]. Whether MP patients immobilized due to general weakness more frequently develop stroke than mobile patients with MPs is currently unresolved. Recent studies concerning this matter have shown that prophylactic anticoagulation is necessary only during the first 4 months following onset of the immobility in all immobile neurological patients, regardless of their muscle tone [36]. The dramatic drop in the risk of venous thromboembolism 3 4 months after onset of the immobility is attributed to vascular changes following long-term inactivity [36].

\section{Cryptogenic Stroke}

A 4-year-old DMD patient developed pontine stroke 3 times within 1 year [37]. Left ventricular function was normal and there was no indication of AFI/AFL [37]. In this case, the diagnosis of DMD is questionable since immunohistochemistry and genetic testing for dystrophin were not available at the time of diagnosis. A 41-year-old male with DM1 experienced a TIA manifesting as aphasia and right-sided hemi-syndrome for $2 \mathrm{~h}$ [38]. Though the authors attributed the cerebrovascular event to mitral valve prolapse syndrome, the proposed causal relation remains questionable.

\section{Metabolic Stroke}

Metabolic stroke is a typical phenotypic feature of MIDs, where it manifests as SLE [39]. SLEs are usually non-ischemic events, characterized by increased capillary permeability, hyperperfusion, neuronal hyperexcitability, and neuronal loss [40]. SLEs present not only with classical clinical features of ischemic stroke, but frequently with additional features, such as epileptic seizures, ataxia, migraine-like headache, visual impairment, amnesia, cognitive impairment, psychosis, hallucinations, confusional state, or coma. SLEs are episodic events and occur most frequently in MELAS syndrome and mimic ischemic stroke, but are largely different concerning imaging, treatment, and prognosis [41]. Other MIDs in which SLEs have been reported include MERRF syndrome, Kearns-Sayre syndrome, and Leigh syndrome [42].

Though the pathogenesis of SLEs is under debate [43], there is consensus that the cerebral lesions seen on imaging (stroke-like lesions, SLLs) represent vasogenic edema. Vasogenic edema may result from mitochondrial microangiopathy, which may lead to cerebral hypoperfusion and thus hypoxia and capillary leakage [44]. Arguments against mitochondrial angiopathy are that ischemic lesions within SLLs are rare, that the prevalence of ischemic stroke is not increased in MIDs, that most MID patients with an SLE have no mitochondrial angiopathy on autopsy, and that cerebral blood flow during or after an SLE is either normal or increased on appropriate perfusion studies [39, 45, 46]. Arguments in favor of mitochondrial angiopathy are that SLLs may occasionally contain ischemic lesions and that COX deficiency and heteroplasmy rates are highest in leptomeningeal or cortical arteries [47]. Most likely, however, an SLL is not due to mitochondrial angiopathy with functional disturbance of arterioles resulting in an ischemic event [48]. According to a second hypothesis, SLL are due to a local metabolic defect in energy production resulting in anaerobic metabolism, neuronal damage or death from acidosis [39], and consecutively hyperperfusion and vasogenic edema [49]. According to a third hypothesis, SLLs result from focal neuronal hyperexcitability, demanding increased provision of energy, and resulting in a mismatch between demand and availability of energy $[43,50]$. An argument in favor of the 'epilepsy' hypothesis is that focal epileptiform discharges are recorded in up to $80 \%$ of patients during an SLE [50].

In the acute stage of an SLL, MRI shows hyperintensity on $\mathrm{T}_{2}, \mathrm{DWI}$, and apparent diffusion coefficient (ADC) mapping, indicating a vasogenic edema [49]. The ADC may remain high even months after onset [49] to become hypointense or alternatively hyperintense in the chronic stage. Occasionally, SLL may go along with petechial or intracortical gyral hemorrhage [43]. In single cases, there may be coexistence of cytotoxic and vasogenic edema within the same SLL [51], particularly at onset of an SLE [52]. The ADC is helpful to differentiate between ischemic stroke (hypointense ADC) and extracellular edema (hyperintense ADC) [53]. SLLs are most frequently located in the parieto-occipital region and show a characteristic dynamic spread to other homo- or contralateral regions [39]. At the end of an SLE, MRI may completely normalize or evolve into laminar cortical necrosis [43], $\mathrm{T}_{2}$ white matter hyperintensities, or cysts.

Perfusion studies by perfusion MRI, HMPAO-SPECT, xenon CT, or PET may be either normal or show focal cortical hyperperfusion in the acute stage of an SLL [43, $45,46,49]$. In the chronic stage of an SLL, diffuse hypoperfusion may be the characteristic feature [54]. Conventional angiography or MRA are usually normal in patients with SLEs [55].

H-MRS of an SLL may show a reduced N-acetyl-aspartate (NAA)/creatine $(\mathrm{Cr})$ ratio and an increased lactate peak $[49,56]$. In the later stages of an SLL, the NAA/ $\mathrm{Cr}$ ratio may gradually increase together with a decrease in the ADC [49]. In several patients, the increase in lactate and glucose and the decrease of NAA, glutamate, or 
Cr are not restricted to the SLL, but may occur ubiquitously within the brain [57].

Due to the lack of prospective controlled studies, there is no agreement on the treatment of SLEs. So far, SLLs have been managed by application of remedy cocktails made up of coenzyme Q, idebenone, L-arginine, tocopherol nicotinate, edaravone, prednisolone, glycerol, ATP, cytochrome $\mathrm{C}$, flavin mononucleotide, thiamine diphosphate, biotin, carnitine, or dichloracetate in various combinations. In other studies, some of these agents have been given in monotherapy, such as creatine monohydrate, cysteamine, or succinate [58]. A recent Cochrane review of 678 abstracts has shown that there is no objective evidence to support the use of coenzyme Q, creatine monohydrate, dichloroacetate, or dimethylglycine for the treatment of MIDs [59].

\section{Conclusions}

Ischemic stroke may be only a rare phenotypic feature of MPs and most frequently occurs in DM1, dystrophinopathies, and MIDs. Metabolic stroke, however, is a dominant feature of various syndromic MIDs, and should be increasingly recognized since the prevalence of MIDs will increase due to improved diagnostic facilities and increasing awareness of MIDs in general. Since SLEs, which may result in a state of disability, characteristically spread and recur, and as there is no effective therapy currently available, all efforts should be directed towards research into the development of targeted, safe and immediately effective agents or a therapeutic concept enabling clinicians to provide support and not to administer unproven medication with unknown side effects.

\section{Appendix: Primary Myopathies}

(1) Muscular Dystrophies (MD)/Dystrophinopathies

Duchenne MD, Becker's MD, X-linked Emery-Dreifuss MD, autosomal-dominant Emery-Dreifuss MD, facioscapulohumeral $\mathrm{MD}$, autosomal-dominant limb-girdle MD, autosomal-recessive limb-girdle $\mathrm{MD}$, and congenital muscular dystrophies (CMDs: CMD with merosin deficiency, CMD with abnormal glycosilation of dystroglycan, Fukuyama CMD, Walker Warburg syndrome, muscle eye-brain disease, rigid spine syndrome, Ullrich syndrome, Bethlem MP, and CMD with integrin deficiency).

\section{(2) Congenital Myopathies}

Nemaline MP, congenital MP with fiber-type dysproportion, myotubular MP, centronuclear MP, central core disease (CCD), multiminicore disease, and hyaline body MP.
(3) Distal Myopathies

Distal recessive MP (Myoshi), tibial muscular dystrophy (Udd), distal MP with rimmed vacuoles (Nonaka), hereditary inclusion body MP, distal MP (Laing), vocal cord and pharyngeal distal MP, adult-onset distal MP, Welander distal MP, distal MP with pes cavus and areflexia (vacuolar neuromyopathy), and distal MP with myotilin defect.

(4) Myofibrillar Myopathies

$\alpha$-Cristalline-related myofibrillar MP, desmin-related myofibrillar MP, desmin-related MP with Mallory bodies, myofibrillar MP with arrhythmogenic right ventricular cardiomyopathy, myotilin-related myofibrillar MP, spheroid body MP, and filamin-Crelated myofibrillar MP.

(5) Autophagic Vacuolar Myopathies

Danon's disease and MP with excessive autophagia.

(6) Myotonic Syndromes

DM1, DM2, Thomson, Becker (see '7'), rippling muscle disease, Schwartz-Jampel syndrome, and Brody disease.

(7) Ion Channel Muscle Diseases

$\mathrm{Cl}$ channel (Thomson, Becker), Na channel (hyperPP, Eulenburg, K-aggravated myotonia, LQT-syndromes), Ca channel (hypoPP), K channel (hypoPP3, episodic ataxia/myokymia, Anderson's syndrome, and long QT syndromes).

\section{(8) Malignant Hyperthermia}

\section{(9) Metabolic Myopathies}

- Gylcogenoses [II (Pompe), IIIa, IV, V (McArdle disease), VII (Tarui), phosphoglycerate kinase deficiency, phosphoglycerate mutase deficiency].

- Glycolytic pathway (lactate dehydrogenase deficiency, enolase deficiency).

- Lipid metabolism [carnitine-palmitoyltransferase (CPT)-deficiency, primary systemic carnitine deficiency, carnitine-acylcarnitine-translocase (CACT)-deficiency, multiple acyl-CoA dehydrogenase deficiency (MADD), very long chain acyl-CoA dehydrogenase deficiency (VLCAD), Chanarin-Dorfman syndrome].

\section{(10) Mitochondrial MP}

\section{(11) Unclassified}

Oculopharyngeal muscular dystrophy, MP with proximal atrophy and early respiratory muscle involvement (Edström), epidermiolysis bullosa simplex, muscle hypertrophy, fibrodysplasia ossificans progressiva, idiopathic hyperCKemia, McLeod syndrome, and Barth syndrome. 


\section{References}

-1 Biller J, Ionasescu V, Zellweger H, Adams HP Jr, Schultz DT: Frequency of cerebral infarction in patients with inherited neuromuscular diseases. Stroke 1987;18:805-807.

-2 Hanajima R, Kawai M: Incidence of cerebral infarction in Duchenne muscular dystrophy. Muscle Nerve 1996;19:928.

-3 Finsterer J, Stöllberger C: Primary myopathies and the heart. Scand Cardiovasc J 2008; 42:9-24.

-4 Finsterer J, Stöllberger C: Atrial fibrillation/ flutter in myopathies. Int J Cardiol 2008;128: 304-310.

5 Boriani G, Gallina M, Merlini L, Bonne G, Toniolo D, Amati S, Biffi M, Martignani C, Frabetti L, Bonvicini M, Rapezzi C, Branzi A: Clinical relevance of atrial fibrillation/ flutter, stroke, pacemaker implant, and heart failure in Emery-Dreifuss muscular dystrophy: a long-term longitudinal study. Stroke 2003;34:901-908.

6 Atsumi M, Tanaka A, Kawarabayashi T, Nishio S, Sakamoto H, Hasegawa T, Kitaguchi M: Cerebral embolism associated with Becker muscular dystrophy-related dilated cardiomyopathy. No To Shinkei 2004;56: 163-167.

-7 Cook AW, Bird TD, Spence AM, Pagon RA, Wallace JF: Myotonic dystrophy, mitralvalve prolapse, and stroke. Lancet 1978;1: 335-336.

$\$ 8$ Ances BM, Sullivan J, Weigele JB, Hwang V, Messé SR, Kasner SE, Liebeskind DS: Stroke associated with Barth syndrome. J Child Neurol 2006;21:805-807

$\checkmark 9$ Rhodes J, Margossian R, Darras BT, Colan SD, Jenkins KJ, Geva T, Powell AJ: Safety and efficacy of carvedilol therapy for patients with dilated cardiomyopathy secondary to muscular dystrophy. Pediatr Cardiol 2008; 29:343-351

10 Ikeniwa C, Sakai M, Kimura S, Wakayama T, Kuru S, Yasuma F, Konagaya M: Two cases of Duchenne muscular dystrophy complicated with dilated cardiomyopathy and cerebral infarction. No To Shinkei 2006;58:250-255.

-11 Díaz Buschmann C, Ruiz Falcó ML, Tamariz Martel Moreno A, García Peñas JJ, Gutiérrez Solana LG, Pérez Jiménez A, Marín C: Repeated cerebral infarction in a patient with Duchenne's muscular dystrophy. Rev Neurol 2004;38:533-536.

12 Kozdag G, Ciftci E, Ural D, Sahin T, Selekler M, Agacdiken A, Demirci A, Komsuoglu S, Komsuoglu B: Silent cerebral infarction in chronic heart failure: ischemic and nonischemic dilated cardiomyopathy. Vasc Health Risk Manag 2008;4:463-469.

13 Engberding R, Bender F: Identification of a rare congenital anomaly of the myocardium by two-dimensional echocardiography: persistence of isolated myocardial sinusoids. Am J Cardiol 1984;53:1733-1734.
4 Stöllberger C, Finsterer J: Left ventricular hypertrabeculation/noncompaction. J Am Soc Echocardiogr 2004;17:91-100.

15 Zaragoza MV, Arbustini E, Narula J: Noncompaction of the left ventricle: primary cardiomyopathy with an elusive genetic etiology. Curr Opin Pediatr 2007;19:619-627.

16 Finsterer J, Stöllberger C, Blazek G: Neuromuscular implications in left ventricular hypertrabeculation/noncompaction. Int J Cardiol 2006;110:288-300.

17 Pascal C, Lefèvre M; Société Française de Cardiologie: Non-compaction of the myocardium in childhood. Arch Mal Coeur Vaiss 2005;98:443-448

18 Pignatelli RH, McMahon CJ, Dreyer WJ, Denfield SW, Price J, Belmont JW, Craigen WJ, Wu J, El Said H, Bezold LI, Clunie S, Fernbach S, Bowles NE, Towbin JA: Clinical characterization of left ventricular noncompaction in children: a relatively common form of cardiomyopathy. Circulation 2003; 108:2672-2678.

19 Fazio G, Corrado G, Zachara E, Rapezzi C, Sulafa AK, Sutera L, Stollberger C, Sormani L, Finsterer J, Benatar A, Di Gesaro G, Visconti C, D’angelo L, Novo G, Mongiovi M, Cavusoglu Y, Baumhakel M, Drago F, Indovina G, Ferrara F, Carerj S, Pipitone S, Novo S: Anticoagulant drugs in noncompaction: a mandatory therapy? J Cardiovasc Med (Hagerstown) 2008;9:1095-1097.

20 Finsterer J, Stollberger C, Mölzer G, Winkler-Dworak M, Blazek G: Cerebrovascular events in left ventricular hypertrabeculation/noncompaction with and without myopathy. Int J Cardiol 2008;130:344-348.

21 Stöllberger C, Finsterer J: Left ventricular hypertrabeculation/noncompaction and stroke or embolism. Cardiology 2005;103:68-72.

-22 Fazio G, Novo G, Visconti C, D’angelo L, Sutera L, di Gesaro G, Indovina G, Novo S: An unusual cause of cerebral cardioembolism in a 33-year-old man due to ventricular noncompaction. Neurologist 2009;15:5152.

23 Oduncu V, Akgun T, Erkol A, Mutlu B: Biventricular noncompaction presenting with stroke. Eur J Cardiothorac Surg 2008;33: 737.

24 Sahin S, Karsidag S: An unusual cause of cardioembolic stroke: isolated left ventricular noncompaction. Neurologist 2009;15:51.

25 Sir JJ, Lee B, Nah JC, Kim YL, Cho WH, Choi SK: Serious cardioembolic stroke resulting from an overlooked left ventricular noncompaction. South Med J 2008;101:969-970.

26 Jenni R, Oechslin EN, van der Loo B: Isolated ventricular non-compaction of the myocardium in adults. Heart 2007;93:11-15.

27 Hatanaka K, Yutani C, Fujieda T, Yamaguchi T: Polymyositis associated with dissecting aneurysm of arteries and intracerebral hemorrhage. Acta Pathol Jpn 1986;36:12171223 .
28 Suwa A, Hirakata M, Kaneko Y, Sato S, Suzuki Y, Kuwana M: Successful treatment of refractory polymyositis with the immunosuppressant mizoribine: case report. Clin Rheumatol 2009;28:227-229.

29 Regan M, Haque U, Pomper M, Pardo C, Stone J: Central nervous system vasculitis as a complication of refractory dermatomyositis. J Rheumatol 2001;28:207-211.

30 White DA, Leonard MC: Acute stroke with high-dose intravenous immune globulin. Am J Health Syst Pharm 2007;64:1611-1614.

31 Finsterer J, Jarius C, Eichberger H: Phenotype variability in 130 adult patients with respiratory chain disorders. J Inherit Metab Dis 2001;24:560-576.

32 Finsterer J: Mitochondrial disorder overlapping with aorto-iliac occlusive disease (Leriche syndrome). Scot Med J 2009, in press.

33 Finsterer J: Is atherosclerosis a mitochondrial disorder? Vasa 2007;36:229-240.

34 Iizuka T, Goto Y, Miyakawa S, Sato M, Wang Z, Suzuki K, Hamada J, Kurata A, Sakai F: Progressive carotid artery stenosis with a novel tRNA phenylalanine mitochondrial DNA mutation. J Neurol Sci 2009;278:3540.

35 Sherer Y, Livneh A, Levy Y, Shoenfeld Y, Langevitz P: Dermatomyositis and polymyositis associated with the antiphospholipid syndrome - a novel overlap syndrome. Lupus 2000;9:42-46.

36 Gaber TA: Significant reduction of the risk of venous thromboembolism in all longterm immobile patients a few months after the onset of immobility. Med Hypotheses 2005;64:1173-1176

37 Matsuishi T, Yano E, Terasawa K, Nonaka I, Ishihara O, Yamaguchi Y, Okudera T: Basilar artery occlusion in a case of Duchenne muscular dystrophy. Brain Dev 1982;4:379-384.

38 Morris LK, Cuetter AC, Gunderson CH: Myotonic dystrophy, mitral valve prolapse, and cerebral embolism. Stroke 1982;13:93-94.

-39 Oppenheim C, Galanaud D, Samson Y, Sahel M, Dormont D, Wechsler B, Marsault C: Can diffusion weighted magnetic resonance imaging help differentiate stroke from strokelike events in MELAS? J Neurol Neurosurg Psychiatry 2000;69:248-250.

40 Iizuka T: Pathogenesis and treatment of stroke-like episodes in MELAS. Rinsho Shinkeigaku 2008;48:1006-1009.

41 Finsterer J: MELAS syndrome as a differential diagnosis of ischemic stroke. Fortschr Neurol Psychiatr 2009;77:25-31.

42 Furuya H, Sugimura T, Yamada T, Hayashi K, Kobayashi T: A case of incomplete KearnsSayre syndrome with a stroke like episode. Rinsho Shinkeigaku 1997;37:680-684.

43 Iizuka T, Sakai F, Suzuki N, Hata T, Tsukahara S, Fukuda M, Takiyama Y: Neuronal hyperexcitability in stroke-like episodes of MELAS syndrome. Neurology 2002;59:816824 
-44 Takahashi N, Shimada T, Murakami Y, Katoh H, Oyake N, Ishibashi Y, Nishino I, Nonaka I, Goto Y: Vascular involvement in a patient with mitochondrial myopathy, encephalopathy, lactic acidosis, and stroke-like episodes. Am J Med Sci 2005;329:265-266.

$\checkmark 45$ Nariai T, Ohno K, Akimoto H, Ohta Y, Nagaoka T, Hirakawa K, Ishii K, Senda M: Cerebral blood flow, vascular response and metabolism in patients with MELAS syndrome - xenon CT and PET study. Keio J Med 2000; 49(suppl 1):A68-A70.

46 Takahashi S, Tohgi H, Yonezawa H, Obara S, Nagane Y: Cerebral blood flow and oxygen metabolism before and after a stroke-like episode in patients with mitochondrial myopathy, encephalopathy, lactic acidosis and stroke-like episodes (MELAS). J Neurol Sci 1998;158:58-64.

-47 Betts J, Jaros E, Perry RH, Schaefer AM, Taylor RW, Abdel-All Z, Lightowlers RN, Turnbull DM: Molecular neuropathology of MELAS: level of heteroplasmy in individual neurones and evidence of extensive vascular involvement. Neuropathol Appl Neurobiol 2006;32:359-373.

48 Molnár MJ, Valikovics A, Molnár S, Trón L, Diószeghy P, Mechler F, Gulyás B: Cerebral blood flow and glucose metabolism in mitochondrial disorders. Neurology 2000;55: 544-548.

-49 Ito H, Mori K, Harada M, Minato M, Naito E, Takeuchi M, Kuroda Y, Kagami S: Serial brain imaging analysis of stroke-like episodes in MELAS. Brain Dev 2008;30:483488.

50 Iizuka T, Sakai F, Ide T, Miyakawa S, Sato M, Yoshii S: Regional cerebral blood flow and cerebrovascular reactivity during chronic stage of stroke-like episodes in MELAS - implication of neurovascular cellular mechanism. J Neurol Sci 2007;257:126-138.
51 Ishikawa N, Tajima G, Ono H, Kobayashi M: Different neuroradiological findings during two stroke-like episodes in a patient with a congenital disorder of glycosylation type Ia. Brain Dev 2009;31:240-243.

52 Tzoulis C, Bindoff LA: Serial diffusion imaging in a case of mitochondrial encephalomyopathy, lactic acidosis, and stroke-like episodes. Stroke 2009;40:e15-e17.

53 Yonemura K, Hasegawa Y, Kimura K, Minematsu K, Yamaguchi T: Diffusion-weighted MR imaging in a case of mitochondrial myopathy, encephalopathy, lactic acidosis, and strokelike episodes. AJNR Am J Neuroradiol 2001;22:269-272.

54 Li JY, Hsieh RH, Peng NJ, Lai PH, Lee CF, Lo YK, Wei YH: A follow-up study in a Taiwanese family with mitochondrial myopathy, encephalopathy, lactic acidosis and strokelike episodes syndrome. J Formos Med Assoc 2007;106:528-536.

55 Klein A, Fasnacht M, Huisman TA, Neuhaus TJ, Martin E, Boltshauser E: Siblings with infantile cerebral stroke and delayed multivessel involvement - a new hereditary vasculopathy? Eur J Paediatr Neurol 2007;11: 292-296.

56 Pavlakis SG, Kingsley PB, Kaplan GP, Stacpoole PW, O'Shea M, Lustbader D: Magnetic resonance spectroscopy: use in monitoring MELAS treatment. Arch Neurol 1998; 55:849-852.

57 Wilichowski E, Pouwels PJ, Frahm J, Hanefeld F: Quantitative proton magnetic resonance spectroscopy of cerebral metabolic disturbances in patients with MELAS. Neuropediatrics 1999;30:256-263.

58 DiMauro S, Rustin P: A critical approach to the therapy of mitochondrial respiratory chain and oxidative phosphorylation diseases. Biochim Biophys Acta 2008, E-Pub ahead of print.
59 Chinnery P, Majamaa K, Turnbull D, Thorburn D: Treatment for mitochondrial disorders. Cochrane Database Syst Rev 2006;1: CD 004426.

-60 Nakajima M, Hirano T, Doi H, Uchino M: Stroke and ventricular dysfunction in a patient with isolated left ventricular noncompaction. Intern Med 2007;46:1251-1254.

-61 Celebi AS, Gulel O, Cicekcioglu H, Celebi OO, Ulusoy V: Isolated noncompaction of the left ventricular myocardium complicated by thromboembolic cerebrovascular accident in a patient with essential thrombocythemia. Int J Cardiol 2008; 128:e22-e24.

62 Baez-Escudero J, Pillai M, Nambi V, Dokainish $\mathrm{H}$ : Comprehensive contrast and 3-dimensional echocardiographic imaging of left ventricular noncompaction cardiomyopathy. Eur J Echocardiogr 2008;9:156-157.

63 Finsterer J, Stöllberger C, Feichtinger H: Noncompaction and endocarditis in suspected mitochondrial disorder. Int J Cardiol 2008;123:e45-e47.

64 Fernández Sánchez LJ, Pérez González R, Guasch Arévalo E, Martín Reyes R, Gilsanz Rodríguez F: Perioperative treatment of a pregnant woman with recent cerebral infarction secondary to noncompaction cardiomyopathy. Rev Esp Anestesiol Reanim 2006;53: 661-664.

65 Walpot J, Klazen C, Sorgedrager J, Hoevenaar $\mathrm{M}$, den Braber J: Isolated ventricular noncompaction in a patient with stroke. Echocardiography 2005;22:690-692.

66 Hasçelik S, Yalnizoğlu D, Kafali G, Celiker A, Cila A, Topçu M, Gürgey A: Stroke owing to noncompaction of myocardium. J Child Neurol 2003;18:437-439. 